\title{
Human Interaction in the Regulatory of Telecommunications Infrastructure Deployment in South Africa
}

\author{
Sharol Sibongile Mkhomazi ${ }^{1}$ and Tiko Iyamu ${ }^{2}$ \\ ${ }^{1}$ Tshwane University of Technology, \\ Department of Office Management and Technology, Pretoria, South Africa \\ mkhomaziss@tut.ac.za \\ ${ }^{2}$ Polytechnic of Namibia, Department of Business Computing, Windhoek, Namibia \\ connectvilla@gmail.com
}

\begin{abstract}
Telecommunications is increasingly vital to the society at large, and has become essential to business, academic, as well as social activities. Due to the necessity to have access to telecommunications, the deployment requires regulations and policy. Otherwise, the deployment of the infrastructures would contribute to environment, and human complexities rather than ease of use.

However, the formulation of telecommunication infrastructure deployment regulation and policy involve agents such as people and processes. The roles of the agents are critical, and are not as easy as it meant to belief. This could be attributed to different factors, as they produce and reproduce themselves overtime.

This paper presents the result of a study which focused on understanding how non-technical factors enable and constrain the development and implementation of telecommunications infrastructure sharing regulations. In the study, the interactions that take place amongst human and non-human agents were investigated. The study employed the duality of structure, of Structuration Theory as lens to understand the effectiveness of interactions in the formulation of regulations, and how policy is used to facilitate the deployment of telecommunications infrastructure in the South African environment.
\end{abstract}

Keywords: Regulatory Authority, Telecommunications, Infrastructure sharing, Structuration Theory, Human Interaction.

\section{Introduction}

Globally, telecommunications infrastructures (broadband) are deployed in urban and rural areas and these infrastructures can be shared. Infrastructure sharing is a concept that advocates on negotiated terms the sharing of network resources within geographical locations by two or more telecommunications network service providers [1]. Sharing telecommunications infrastructure limits duplication and, enhances investment, product innovation and improved customer services [2], and reduces the 
infrastructure deployment costs for network service providers. It is further supported by [1] that building shared networks will lower the operators' capital investment and increase infrastructure roll-out speed. However, the amount that an operator can save depends upon the depth of sharing arrangements [2].

The deployment and performance of shared telecommunications infrastructure (such as broadband) is significantly influenced by different national regulatory institutions, political processes and regulations [3]. These network infrastructures need to be managed and maintained with sound regulatory systems. In one of its strategic documents of [4] stated that the rapid rate, at which broadband technologies are deployed, requires regulations and policies for its guidance. INTEL's articulation and proposal for regulations and policies are mainly to avoid irregularities in the deployment, as well as to improve the technologies' efficiency and effectiveness.

Regulation plays an important role in the telecommunication industry. Regulatory structures represent key factors for innovative processes in the infrastructure sectors as they guide the direction of development and deployment of technology infrastructure [5]. These include price regulation, rules on network accessibility and environmental regulations. Therefore its sustainability relies on the legislation and regulatory structures of the country [6]. With distributed infrastructure and innovative regulations, telecommunication infrastructures such as broadband can provide high-end services to the business sector, as well a range of low-cost, high-quality services to all [7].

This article presents the use of duality of structure from the perspective of Structuration Theory to understand the effectiveness of regulatory in facilitating the deployment of shared telecommunications infrastructure. The focus is to understand how non-technical factors enable and constrain the development and implementation of telecommunications infrastructure sharing regulations.

\section{Research Approach}

To understand the factors that influence the formulation of regulations and policies which guided the telecommunications infrastructure deployment, a real-world situation was solicited through the case study and qualitative methods. [8] described the case study as method for eliciting natural setting. Qualitative research is a good inquiry process of understanding a social context [9]. In this vain, [10] described the method as a process which allows experience or perceptions to be shared. Based on the objectives of the research which was to understanding how non-technical factors enable and constrain the development and implementation of telecommunications infrastructure sharing regulations, probing of response was essential. The qualitative method allows for follow-up such was "why", "how", and "what" [11].

Capricon Regulatory Authority (CRA) was selected for the study. CRA is the main regulatory body in the South Africa. The organisation was instituted under the South African act of 1994. A total of four employees were interviewed within the organisation. The interviewees included two senior managers and two junior staff members. Owing to the current processes of formulating and amendment of broadband and infrastructure sharing regulation, the researcher was limited to only a few interviewees. This also contributed to the adoption of interviews as the single source of data collection. 
The interviews approach was used in the data collection [12]. [13] described the interviews approach as a data collection method that produces first-on-hand accounts of experience, opinion, and perception from the respondents. The interviews were carried out by closely following the interview guide as follows:

i. the purpose of the study was explained to each participant before the interview started;

ii. the interviewees were informed that their confidentiality and anonymity were assured;

iii. the interviewees' rights for participating in the study were explained to each of them;

iv. contact details were given to the participants for any queries regarding their rights.

The interview guidelines were to ensure consistency and uniformity in the data collection. This was followed by presenting all participants with the same demographic interview questions regarding the individual's position in the organisation and occupation. The use of an interview guide ensured that there was some structure and consistency to the interviews, even though the interviews were treated as conversations during which the interviewer elicited detailed information and comments from the respondents.

Data was analysed using Structuration Theory's (ST) duality of structure as a lens to understand how and why interactions amongst actors were carried out in the manner that they did, in attempt to develop and implement telecommunication infrastructures sharing regulations. ST is a theory which constitutes agents and structure within a social phenomenon. The social structure is drawn upon by agents, to consciously or unconsciously produce and reproduce their actions [14]. [15] argued that ST allows us to examine how people (agents) enact structures which shape their emergent and situated use of technology as they interact with it in their ongoing practices. For this study ST provided the steps that needed to be followed in terms of understanding why things happen the way they do within the development and implementation of telecommunications infrastructure sharing regulations. This was instrumental for following the necessary and sequence of steps to understand why certain things are considered significant; how the available facilities are used to enable and constrain processes and activities during regulatory development and implementation.

\section{Telecommunication Infrastructure Deployment Regulation}

The deployment of telecommunications' infrastructures includes technologies that enable high speed transfer of multi-media and high bandwidth information [16]. The deployment of telecommunications' infrastructures is socio-technical in nature [5]. This is primarily because of the technical and non-technical such as people and process components that are in involved in the deployment. Many countries, including South Africa ensure that legal requirements are met as part of the processes for telecommunication's regulatory matter [7]. 
Regulation is critical role on how and where telecommunications infrastructure are deployed and shared. Apart from the geographical location, regulatory structures have a major impact not only on the functioning and performance of national telecommunications but also on the comparative global performance of telecommunications [17]. [18] argued that the role of regulations is important in investment decision making of telecommunication companies as it helps to determine or shape the direction of their return on investment (ROI).

In South Africa regulatory and policy activities in telecommunication markets are strictly regulated by CRA. It is the sole telecommunications regulator in the country maintaining a competitive and socially responsive communications industry. South Africa derives its legislative mandate from the country's Telecommunications Act of 1996, Competition Act of 1998, the Broadcasting Act of 1999, the CRA Act of 2000 and the Electronic Communications Act of 2005 (ECA) [7]. The CRA develops regulations and policies, issues licenses to telecommunications companies, and also manages the frequency spectrum [19].

Telecommunication infrastructures are increasingly unconditional for information societies across the world. Telecommunication infrastructure facilitates, support and enable transparent system, wider dissemination of information, as well as guarantees freedom of speech for technology users [20]. Therefore the effectiveness of regulatory policies is critical in facilitating infrastructure deployment and sharing arrangements among the telecommunication companies, and the communities. The expansion of telecommunication infrastructure through sharing of infrastructure is a strategic process that necessitates co-operation among competitors, and it is subject to explicit involvement by telecommunication regulatory authorities to enforce implementation.

\section{Structuration View of Telecommunication Regulatory Development}

The formulation of regulations for telecommunications infrastructure was carried out within rules and regulations of the country. The regulations facilitate the telecommunications operations in terms of infrastructure deployment. The resources required in the formulation and implementation of telecommunications regulations included technology and people. There were also processes involved.

The organisation, CRA employed both internal and external rules and regulations when formulating the governance and guidance for telecommunication's activities. The internal rules and regulations (standards and procedures) were based on the organisation's objectives and strategy. The external rules and regulations were mainly from the stakeholders including the National Government and Municipal authorities of the country. This made the formulators of the regulations and policies to be powerful.

\section{- Duality of Structure: Signification and Communication}

The CRA formulation of regulations for telecommunications infrastructure was carried out within rules and regulations of the country. One of the criticalities for the development and implementation of regulations and policies was to guide against 
telecommunication service providers deploying infrastructures in locations as they so wish. The regulations and policies were considered to be of important to the service providers as it provides an umpiring status amongst them. This controlled competitiveness in the deployment of their infrastructures, particularly in areas considered to be strategic. However, there seemed to be a gap in CRA's infrastructure deployment regulations. The implications of the gap in the regulations and policies resulted in inappropriate deployment of telecommunications infrastructure in the different locations across the country. One of the employees of CRA briefly explained that "the incumbents are using the limitation of regulations to their defence for not deploying telecommunications infrastructure appropriately".

There are also external rules and processes such as municipality bylaws that were regarded as critical to the deployment of telecommunications infrastructure. However the challenge is that these rules are not formulated in conjunction with the organisation (CRA), and has a major impact on how telecommunications infrastructure could be deployed in the country. This could be attributed to lack of information sharing or different interpretations of shared information. One of the managers, explained that "There are different municipal bylaws guiding the deployment of infrastructure, and that the inconsistencies in municipalities' bylaws created a complicated process for operators deploying telecommunications infrastructure in different locations".

This lack of communication among agents involved in the development and implementation if telecommunication regulatory was considered to be an integral part of regulatory development and implementation plans. The stakeholders who were involved in formulating telecommunications regulations and policies were expected at all times, to understand the importance of regulating the telecommunications industry. The structures and channels that were required were also understood by the stakeholders. However, the structures amongst other factors gave some individuals and groups certain power, and source of domination.

\section{- Duality of Structure: Domination and Power}

As already established, the formulation of regulations and policies for the deployment of telecommunications infrastructures in the country was the responsibility of the CRA by virtue of the mandate bestowed upon them by the Ministry of Communications, as allowed by the constitution of the country. The CRA therefore formulated regulations to facilitate and manage the deployment of shared telecommunications infrastructures.

The organisation had policy that guided how telecommunications infrastructure could be shared among the telecommunications companies. The policy was named or tagged "Facility Leasing". The Facility Leasing regulations was formulated to help facilitate efficient and appropriate infrastructure deployment. One of the employees explained that: "the facility leasing regulation defines the essential facilities that network operators (telecommunications companies) could use or apply in the deployment of their telecommunications infrastructure”. However, there seem to be some challenges in the finalisation of the Facility Leasing regulations. As a result, the telecommunications companies have not been able to apply the regulation in some areas such as sharing of the spectrum technology. The challenges include technical 
know-how to properly define and articulate technologies terms of reference for the telecommunications companies. One of the employees expressed himself as follows: "there are many challenges with the Facility Leasing regulation, as a result, it is not executable. This is because it was not properly developed". The challenge was attributed to lack of availability of sufficient resources such as skilled people. The lack of available skilled personnel was attributed to insufficient funds. Two of the interviewees explained that "the organisation do not receive enough funds which would enable them to recruit qualified skilled personnel. This therefore impacted the quality of regulations and policies that we formulate".

Unfortunately the organisation depended on the Government for funding in order to carry out their mandates. The implication of such dependent led to control and political manipulation of the organisation's activities. Through this type of funding model, the government asserted its power and dominance over CRA and the telecommunications companies in the country. At the time of this study, this was the norm and was legitimised and accepted by the stakeholders such as the telecommunications companies, the communities and CRA.

\section{- Duality of Structure: Legitimation and Sanctions}

As already established above, CRA provided governance, and were the custodian of all regulatory development and implementation in the telecommunication industry. However, legitimation and approval of CRA activities which were driven through three-way dimensional approach: the CRA, Department of Communications, and the Minister of Communications had an impact on the efficiency of regulatory and policy by CRA. One of the managers tried to explain the process and rational for the approach as follows: "the Department of Communication was the bridge between the CRA and the Minister. That the communication between CRA and the Minister has to go through the Department of Communication, this was based on the 1994 government on which the CRA was established".

The formulation and implementation of regulations and policies were also guided by external and internal rules and interests. The bylaws were fundamental in that each of the geographical location across the country had its unique requirements. One of the interviewees pointed out: "It was a very complicated process for the telecommunications operators to deploy infrastructure in different locations, and that the challenge was due to lack of coordination in addressing the different bylaws set by municipalities". Despite the challenges, the CRA, government and the communities accepted the development and implementation of the regulations that facilitated the telecommunications' activities in the deployment of infrastructures in the country.

\section{$5 \quad$ Factors Influencing Telecommunication Regulations and Policies}

From the analysis presented above, some factors were found to influence the formulation of regulations and policing which guided the telecommunications infrastructure deployment as depicted in Figure 2, and discussed below. 


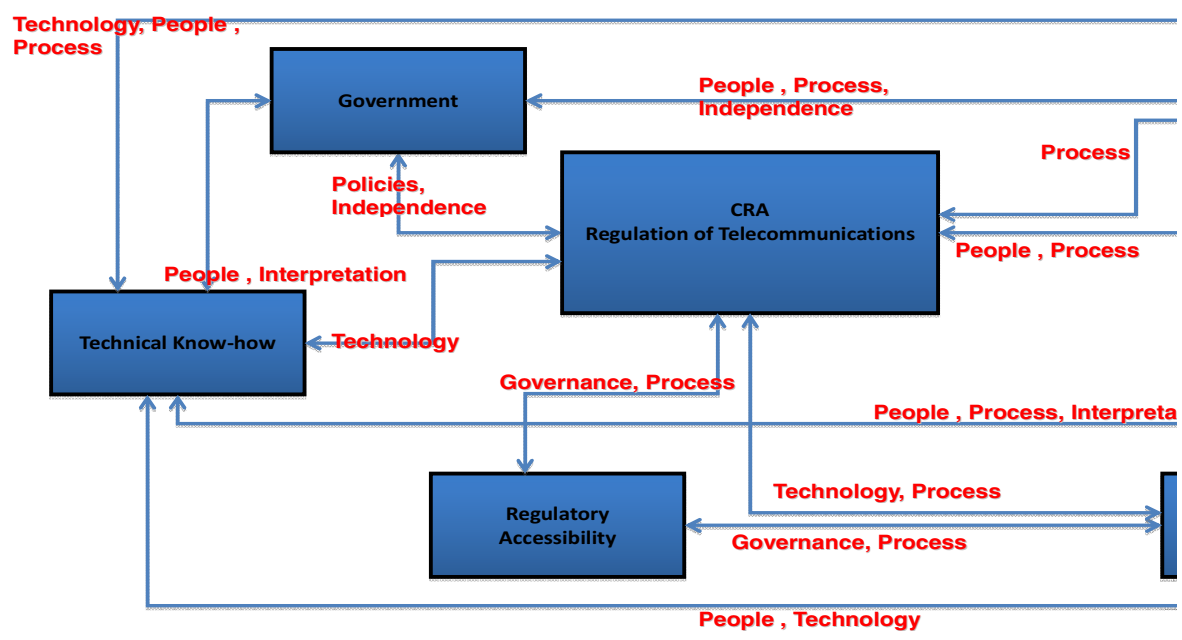

Fig. 1. Components of telecommunication regulatory

\section{- Government}

The interest and role of the government was defined around power to control the activities of the telecommunication through the establishment of CRA. By so doing, the government created obligatory passage point for CRA, meaning the organisation could not act based on its own assertion. This had negative impact on the operations of the organisation. For example, their privilege to access funds for its operations was not based on their scope of activities, but on the discretion of the Minister of Communication, which sometimes created uncertainty. However, there were some positive implications of government interference in CRA activities. It gave the organisation the political strength and muscle to manage and get the telecommunication to adhere to its regulations and policies. The government interference was a manifestation of politics which emanated from interactions amongst the agents of the stakeholders.

\section{- Organisational Politics}

The organisational politics as experienced by CRA was influenced by many different factors, such as power to control and signification of presence, from both internal and external sources. The politics were driven by the government interests in the activities of CRA. This in-turn impacts the types and quality of service that the communities get from the telecommunication companies overtime and space of occurrence.

Also, the manifestation of politics ignited the decision to sometime withheld fund, which deprived the CRA from recruiting qualified personnel, which sometimes derailed activities, as revealed in the analysis. Organisational politics and organisational structure influence, and depend on each other to exist and make a difference. As such, it is difficult, or lack of sustenance to address one without the other. 


\section{- Organisational Structure}

The organisational structure of CRA was relied upon in the distribution and allocation of tasks when it came to formulation of regulations and policies for the deployment of telecommunication infrastructures. On another hand, the structure of the organisation shaped the both interaction and relationship between CRA and the government, as well as the telecommunication companies.

Somehow, the structure of the organisation was not clear and transparent, at least to external stakeholders. The organisational structure of CRA was interpreted by some stakeholders as complicated, and as well undermined by some influencing factors or agent such as the government. This was attributed to ineffectiveness in CRA performance of its activities because the Minister of Communication played a dominant role in the organisation's recruitment process. The Minister appointment of CRA's Council member made it difficult for the organisation to make decisions that were contrary to Government's interest. Also, the organisational structure influenced and shaped the technical know-how in the formulation of regulations and policies in the deployment of telecommunications' infrastructures in the country.

\section{- Technical Know-How}

To implement sufficient and efficient regulations it was crucial to have skilled and competent employees within the organisational structure. The organisation lacked sufficient skilled people to carry out its strategic objective. Although the people formulate regulation, they cannot implement it. There was a need for skilled people with the appropriate technical know-how as it is a lack of such knowledge that causes problems with regulations such as spectrum sharing.

Another factor contributed to lack of technical know-how was the Government's intervention and the organisation dependence on government for funding. These have led to CRA not being able to employ the appropriate skilled persons to fulfil the role of regulating and implementing telecommunications regulations and policies.

\section{- Communication}

The effect of the organisational politics shaped and influenced how information was communicated, and interpreted by employees as well as the stakeholders. Some employees including stakeholders shared and interpreted information in accordance to their personal interests. In the same vain, others understood their roles and responsibilities based on their interest. Unfortunately, the information and their interpretations were followed in executing their daily activities.

Another critical aspect was that the communication within the organisation took a different shape from the communication which happened externally, between the CRA, and the government, as well as the telecommunications companies. Due to factors such as organisational politics, and organisational structure, communication channels were not effective, messages did not reach audiences accurately. This has an impact on the deployment of shared telecommunications infrastructure in the country. 


\section{- Regulatory Accessibilities}

The communication channels had an impact on how information was shared in the organisation. Based on our empirical evidences, it is fair to say that information sharing, and access to processes and procedures were limited in CRA. This had impact on the end-product, regulations and policies procedures which resulted in some regulation such as Facility Leasing not being easy to implement by telecommunications organisations.

\section{Conclusion}

The study has empirically proven and revealed that the role played by non-technical factors such as people, processes and politics are critical to the development of telecommunication regulations and policies. The factors have a major impact on the effectiveness and efficiency in regulatory development and implementation. The study would therefore be important to telecommunications managers, the regulatory authority, government, as well the communities at large to gain better understanding of the impact and implications of the actions of non-technical factors.

The use of duality of structure from the perspective of Structuration Theory (ST) was useful in understanding how events and activities were produced and reproduced overtime and space in the formulation of regulations policies for the deployment of telecommunication infrastructures in the country. Within the frame of the duality of structure, it was possible to follow the interactions which took place amongst the agents, and understand how significant was associated to facilities, and how events transformed themselves and become norm. This would be difficult or impossible to achieve without ST.

\section{References}

1. Berkers, F., Hendrix, G., Chatzicharistou, I., De Haas, T., Hamera, D.: To Share Or Not To Share? Business aspects of network sharing for Mobile Network Operators. In: ICIN, BMMP Workshop, Berlin (2010)

2. Chanab, L., El-Darwich, B., Hasbani, G., Mourad, M.: Telecom Infrastructure sharing: Regulatory Enablers and Economic Benefits (2007),

http://www.boozallen.com/media/file/Telecom_In

3. Naidoo, R., Kaplan, D., Fransman, M.: The South African Telecoms Innovations Systems and teh Diffusion of Broadband (2005), http://radian.co.za/docs/BROADBAND_paper_final.pdf

4. INTEL.: Realising the benefits of Broadband. White Paper (2009), http: / / www. intel.com/content/dam/www/publications

5. Markard, J.: Characteristics of infrastructure sectors and implications for innovation processes. Discussion paper for the Workshop on Environmental Innovation in Infrastructure Sectors (2009)

6. Roman, E.S.: Bringing broadband access to rural areas: A step-by-step approach for regulators, policy makers and universal access program administrators. Paper presented at the Nineth Global Symposium for Regulators, Beirut, Lebanon (2009) 
7. Gillwald, A.: Case Study: Broadband the case of South Africa. Paper presented at the ITU Regulatory Implications of Broadband Workshop (2001), http : / www . itu . int / osg/spu/ni/broadband/workshop/southafricafinal.pdf

8. Yin, R.K.: Case study research: Design and methods, 4th edn., California (2009)

9. Cresswell, J.W.: Research designs: Qualitative, quantitative and mixed methods approaches, 2nd edn. Sage Publications, Thousand Oaks (2003)

10. De Vos, A.S., Strydom, H., Fouche, C.B., Delport, C.S.L.: Research at Grass Roots: For the social sciences and human service professions. Pretoria, Van Schaik (2002)

11. Saunders, M., Lewis, P., Thornhill, A.: Research Methods for Business Students, 4th edn. Prentice Hall, Harlow (2007)

12. Babbie, E.: The basic of social research, 3rd edn. Thomson, Canada (2005)

13. Polkinghorne, D.E.: Language and meaning: Data collection in Qualitative research. Counselling Psychology Journal 52(2), 137-145 (2005)

14. Giddens, A.: The Constitution of society: Outline of the theory of Structuration. University of California Press, Berkely (1984)

15. Orlikowski, W.J.: Using technology and constituting structures: A practice lens for studying technology in organisations. Organisational Science 11(4), 404-428 (2000)

16. Papacharissi, Z., Zaks, A.: Is Broadband the future? An analysis of broadband technology potential and diffusion. Telecommunications Policy 30, 64-75 (2006)

17. Fransman, M.: Global broadband battles: Why the US and Europe lag while Asia leads. Standford University Press, Standford (2006)

18. Sutherland, D., Aranjo, S., Egert, B., Kozluk, T.: Infrastructure Investment: Links to growth and the role of public Policies. OECD Economic department Working Papers, No 686. OECD Publishing (2009)

19. Tweheyo, A.: Spectrum Management Policy framework for mobile communication: A case study of Uganda (2009), http: / d space.mak. ac .ug / bitstream/ $123456789 / 600 / 3 /$ twehenyo=asaph-cit-pgd-report.pdf

20. Chinn, M.D., Fairlie, R.W.: The Determinants of the Global Digital Divide: A crosscountry analysis of computer and Internet penetration. Institute University of Wisconsin, Madison (2004) 